\title{
ECOFEMINISMO, ESTRATÉGIAS E PRÁTICAS DE CUIDADO COM A VIDA Fragmentos de uma narrativa-biográfica enquanto morriam os vampiros de galinhas
}

\section{ECOFEMINISM, STRATEGIES AND LIFE CARE PRACTICES Fragments of a biographical narrative while chicken vampires died}

\author{
Luísa de Pinho Valle - CES/Universidade de Coimbra - \\ luisadepinhovalle@gmail.com/luisavalle@ces.uc.pt
} Com: Annalisa Bellu ${ }^{1}$ - annalisabellu@icloud.com

\section{RESUMO}

Proponho compartilhar um diálogo de saberes sobre as estratégias e práticas do cuidado com a vida humana e não-humana -, a partir de uma análise inicial da experiência com uma investigação-ação participante que está em construção. Na referida pesquisa busco coconstruir narrativas biográficas de/com seres que se representam e se identificam como mulheres que formam parte constitutiva e constituinte de meu trabalho de doutoramento ${ }^{2}$. Estas narrativas são entrelaçadas nas práticas da realização da agroecologia, ou numa agricultura equilibradamente ecológica. Para tanto, parto de uma hermenêutica ecofeminista em diálogo com as bases conceituais das Epistemologias do Sul. Minha pesquisa é feminista, epistemológica e metodologicamente. Assim, desenvolvo um trançado entre as narrativas das mulheres coparticipantes da pesquisa em curso e uma leitura pluriepistemológica que privilegia os ecofeminismos, a ecologia política, o pós-colonialismo e a decolonialidade. Os conhecimentos são sempre situados, num contexto específico, formado e (trans)formador de subjetividades diferentes que ocupam um espaço comum. Desta forma, dialogo neste artigo com Annalisa Bellu, na aldeia de Campo Benfeito, região da Beira Alta em Portugal, a fim de identificar prática-transformadora de cuidado pela e com a vida, por ela realizados na sua cotidianidade. Objetivo trazer à evidência algumas fraturas concretas às linhas abissais divisoras das realidades do mundo moderno engendradas nas práticas e pensamentos ecofeministas.

PALAVRAS-CHAVE: Ecofeminismos; Epistemologias do sul; Narrativas biográficas. \begin{abstract}
I propose to share a dialogue of knowledge about the strategies and practices of caring life - human and non-human -, based on an initial analysis of the experience with a working participatory action research. To do so, I aim to co-construct biographical narratives on/ with social actors that represent and identify themselves as women who form a constituent part of my $\mathrm{PhD}$ thesis. These narratives are intertwined in the practices of agroecology, or in a balanced ecological agriculture. To be sure, I start from an ecofeminist hermeneutics in dialogue with the framework of Epistemologies of the South. I develop a feminist research from both epistemological and methodological views, as I promote a creative twist between the narratives of women co-participating in the ongoing research and a pluriepistemological perspective that privileges ecofeminisms, political ecology, post-colonialism and decoloniality. The

\footnotetext{
${ }^{1}$ Esclareço que utilizo a preposição com para a autoria do presente trabalho em alusão à companhia, ao conteúdo e ao entendimento acordado entre a autora da análise teórica elaborada e a pessoa que apresentou no campo concreto da pesquisa as nuances, possibilidades, experiências e a própria estória que fundamentam e dão os elementos constitutivos do presente artigo.

${ }^{2}$ A referida investigação é realizada no âmbito do doutoramento Democracia no século XXI, do Centro de Estudos Sociais da Universidade de Coimbra e é financiada pela Fundação para Ciência e Tecnologia - FCT, Portugal.
} 


\section{Nanduty}

ISSN:2317-8590

knowledge is always situated, in a specific context, formed and (trans)forming different subjectivities that pave a common space. In this sense, I dialogue with Annalisa Bellu, from the village of Campo Benfeito, region of Beira Alta in Portugal, in order to identify practice-transforming care for/with life, performed in her daily life. Our goal is to highlight some concrete fractures to the abyssal lines divided from the realities of the modern world that were engendered through ecofeminist practices and thoughts.

KEYWORDS: Ecofeminisms; Epistemologies of the South; Biographical narratives.

\section{INTRODUÇÃO}

Neste trabalho apresento um fragmento das minhas reflexões iniciais desenvolvidas na pesquisa de campo que faz parte de investigação doutoral em construção. A pesquisa em referência tem como finalidade contribuir para uma sociologia crítica ecofeminista e pós-colonial desde uma articulação teórica transnacional entre feminismos e Epistemologias do Sul e apoia-se tanto em análise teórica e documental como numa etnografia em duas realidades coexistentes em suis não-imperiais. Esclareço que invocar suis não-imperiais, como explica Teresa Cunha (2015), faz sentido, pois mesmo contemporâneo de outros Nortes e Suis, o

[...] uso do prefixo 'não' junto a 'imperial' sublinha, antes de mais, as minhas (nossas) ignorâncias sobre esse Sul subsumido pela sombra que lhe foi lançada para, em seguida, destacar os sinais que dele recebemos e do seu dinamismo inventivo, polirracional, criativo e perguntador. (CUNHA, 2015: 15)

Nisto está a possibilidade do novo, a abertura de redes de significados outros que não necessitam estar presas às normas androcêntricas, antropocêntricas e logocêntricas, do que se convencionou reconhecer por conhecimento científico, para existirem e serem legítimas. As narrativas biográficas das pessoas que fazem parte constitutiva da minha investigação são de mulheres. É dizer, são de seres que se pensam e/ou representam como mulheres. Em especial, direciono a investigação sobre as suas estórias, práticas, conhecimentos e inovações realizadas numa agricultura fortemente equilibrada com os ecossistemas dos espaços onde vivem. Para tanto, reconheço que, além da consistência e coerência teóricas escolhidas dentro do universo dos feminismos, a troca, a escuta, o olhar atento às dinâmicas e multidireções do fluxo ininterrupto do estar e fazer a vida no espaço físico no qual participo e compartilho de e com outras 


\section{Nanduty}

ISSN:2317-8590

subjetividades que não são a minha, e ao mesmo tempo também fazem parte da minha própria estória, exige meu esforço de descentramento e autorreflexão permanentes.

A confiança e a aceitação nas inter/intrarrelações necessitam de tempo para que o processo do conhecer, participar e estar presente possa, ou não, acontecer entre mim e a outra pessoa. O encontro então, se possível, viabiliza a conformação de uma teoria ecofeminista concreta que contextualmente abraça, cuida, produz e mantém a continuidade da vida - na forma que essa se apresentar. Procuro, assim, realizar uma pesquisa sentipensante que, como elucidado por Fals Borda (2009), reúna o sentimento experimentado e compartilhado com os seres-mulheres em seus espaços/cotidianos, com os conhecimentos guardados, outros descobertos, outros questionados e revisitados para a elaboração dessa teoria ecofeminista conformadora da produção incessante da vida. Metodologicamente, alinho-me a Patrício Guerrero (2010) e abraço o corazonar para, num esforço autorreflexivo e atento às estruturas colonizadas e colonizantes do meu pensamento - que agregam minhas próprias experiências acumuladas -, articular as dimensões afetivas, éticas, políticas e racionais na produção de conhecimento.

Desta forma, alinho-me a Guerrero (2010) quando ele esclarece que:

La sabiduría nos ha enseñado que es necesario construir un pensamiento desde la afectividad, que debemos empezar a corazonar, a sentipensar la vida, si queremos reintegrar la humanidad que nos fragmentó la razón hegemónica de occidente. Sabemos que corazonar, que sentipensar, que hablar desde el cuerpo, desde el corazón, tiene un carácter político insurgente, pues la sabiduría Nasa nos enseña que es en el corazón en donde está el poder para la construcción de la memoria, pues recordar es volver a pensar desde el corazón. (GUERRERO, 2010: 487)

Corazonar é o construir nos encontros com a outra, com o outro, formas de alteridade marcadas pela afetividade. É o significado e significação do sentimento presente na necessidade vital abraçada noutra compreensão sobre e para todas as dimensões da vida, do espaço e do tempo. É a expressão, talvez, mais ampla, alargada, capaz de produzir outro ethos planetário tão urgente em nossos dias.

Isto porque compreendo que nossa humanidade, melhor dito: nossas sociedades humanas dominantes, ao longo da modernidade, desenvolveram uma cultura de guerra contra os povos e 


\section{Nanduty}

ISSN:2317-8590

contra ao que se convencionou chamar de natureza. Como afirma Vandana Shiva (2013) vivemos em pleno eco-apartheid planetário. Ou seja, a guerra é contra a vida. Nessa direção, importa trazer à evidência que os megaprojetos de extrativismos sobre os recursos naturais, as migrações a cada dia mais intensas, a fome, a falta de água potável, a desertificação dos solos, a extinção de espécies etc., estão todos relacionados à ordem do sistema capitalista moderno que, iniciado com o comércio do Atlântico (FEDERICI, 2014, 2018; MIES; SHIVA, 2014; QUIJANO, 2000, 2009 \& SVAMPA, 2013), declarou guerra à Terra e às gentes com o fím único da acumulação do capital para uma ínfima parcela da população mundial ${ }^{3}$.

Como demonstra Maria Mies (2014), com o firmamento do capitalismo moderno o uso da violência como arma econômica foi universalizado, intensificada sobremaneira a qualquer outro sistema, anteriormente, existente. A continuidade dos processos que caracterizaram a primeira fase do capitalismo moderno e a consequente reestruturação da economia mundial contemporânea evidencia que o acordado entre as potências econômicas hegemônicas sobre desenvolvimento para alguns demanda, obrigatoriamente, a destruição daquelas e daqueles que não estão inseridas/os nas estruturas do poder global, assim como os recursos presentes nos diferentes ecossistemas do planeta.

Para alterarmos esse ethos destruidor da vida o corazonar aponta para a cultura do cuidado que, no dizer de Maristella Savampa (2015), possibilita novas inspirações, valores e princípios orientadores para as relações entre humanos, entre essas e esses seres com a natureza e todas as demais alteridades: um ethos procomumal. E cuidar, como definido em outro trabalho juntamente com Teresa Cunha e Cristina del Villar-Toribio (2019), é o pensar-agir descentrando-se de si; é prestar atenção; é solicitude; é desvelo; é preocupação e inquietação pelo bem-estar de outrem; é afeição vital pelos bens comuns; é sentir com e é querer sentir com; é uma forma profunda de partilhar a responsabilidade pela vida em todas as suas formas.

\footnotetext{
3 Para melhor apuração dos números/ínidces da desigual riqueza acumulada no mundo, relativamente ao ano de 2018, verificar o Relatório Global de Riqueza do Credit Suisse Research, October 2018, diponível em: https://www.credit-suisse.com/about-us/en/reports-research/global-wealth-report.html
} 


\section{Nanduty}

ISSN:2317-8590

Defendo que o cuidado não é apenas uma questão social nem diz respeito somente à domesticidade. Contrário à ética reacionária do cuidado (PÉREZ OROZCO, 2006; 2017), estigmatizada ao longo de séculos pelo sistema homogeneizante, hierárquico e antagônico, da ordem capitalista moderna que alimenta e reinventa, sistematicamente, um sistema heteronormativo de domesticação, desqualificação, subordinação e essencialismo da mulher, o cuidado aqui defendido contém dimensões ontológicas, epistemológicas e sociais que oferecem práticas e compreensões outras para a construção desse ethos procomunal (SVAMPA, 2015; PÉREZ OROZCO, 2006; 2017; CUNHA; VALLE; VILLAR-TORIBIO, 2019; BOFF, 1999; 2000).

Dedico-me, então, à análise das narrativas de vida de mulheres que praticam uma agricultura contextualizada que respeita, cuida e mantém o equilíbrio do ecossistema onde estão, em especial. Isto porque, para além de compreender que os seres-mulheres, ou aqueles que se representam ou se pensam como mulheres, são o grupo humano que mais violências e marginalizações sofrem milenarmente (MURARO, 2002; FEDERICI, 2014; MIES, 2014; CUNHA, 2017; entre outras), são elas, também, quem vem disseminando outras culturas e práticas de produção alimentar contrárias às impostas pelo mercado hegemônico global. É dizer, a produção de alimentos sem o uso de agrotóxicos ou químicos industriais, a conservação e reprodução de sementes crioulas, livres de contaminação e que não danificam o ciclo da vida natural (terra, água, fogo, ar e éter), vem sendo protagonizada pelas mulheres em todo o planeta (PINTO, 2009; SHIVA, 2018; FEDERICI, 2018).

Ultrapassados os esclarecimentos preliminares acerca do pluriverso sociológico contido na investigação em curso, no presente artigo compartilho análise elaborada a partir de fragmentos de uma conversa com Annalisa Bellu ${ }^{4}$ ocorrida numa manhã ensolarada de verão, em julho de 2019. Naquele momento ela e eu conversávamos sobre a sua estória e as relações que ela desenvolveu com e na agricultura, enquanto, ao mesmo tempo, ela limpava um dos seus oito galinheiros, ao pé de sua casa. Estávamos, eu e ela, na aldeia de Campo Benfeito, onde convivi com ela e demais

\footnotetext{
${ }^{4}$ A partir desse momento passo a chamar Annalisa Bellu somente por Anna.
} 


\section{Nanduty}

ISSN:2317-8590

moradoras, moradores e familiares da terra, no período entre junho e setembro de 2019. As estórias narradas pela Anna naquela manhã, ao longo de quase duas horas de trabalho realizado para o bem-estar de suas galinhas, fazem parte da sua biografia.

Apresento então, a seguir, uma análise ecofeminista a partir da narrativa da Anna, da sua estória, a fim de identificar as estratégias e práticas do e para o cuidado com a vida por ela desenvolvidos, seja para a vida humana ou não. Dito de outra forma, o entendimento teórico-prático construído na pesquisa é ecofeminista e compreendo ecofeminismo a partir das formações orgânicas protagonizadas por seres-mulheres que resistem e transformam, mesmo sem o dizerem, realidades estruturadas e atravessadas pela ordem do sistema patriarcal-capitalista-colonial moderno. Da identificação de prática de cuidado costuro a análise com as linhas da conformação da pluralidade dos pensamentos ecofeministas que, esclareço: surgem da inspiração de fontes variadas de feminismos (como: o comunitário, pós-colonial, ecológico, radical, decolonial, entre outros), mas que convergem na compreensão da finitude e vulnerabilidade, além de afirmarem a ecodependência de toda manifestação de vida (VALLE, 2017; 2019a; 2019b). Ou seja, o exercício equilibrado de criação, formação e expansão de saberes, constituído de polirracionalidades para as quais o ambiente não é o entorno onde os seres humanos vivem, mas a matriz pluriversal e vital sem a qual a sua existência não seria possível e não teria sentido (CUNHA \& VALLE, 2019), significa a prática ecofeminista de cuidado que conduz o presente trabalho.

Desta forma, divido o artigo em três momentos: 1/ primeiramente apresento o ser-mulher Annalisa Bellu e o lugar onde ela desenvolve uma agricultura contextualizada e ecologicamente equilibrada, Campo Benfeito; 2/ em seguida, elaboro a partir do diálogo com a Anna uma análise teórica acerca das experiências por ela vividas e narradas para identificar algumas práticas e estratégias presentes na sua estória narrativa dividida em duas partes: i) origem, o encontro com a terra e o cuidado pela e com a vida; ii) a descoberta da permacultura e o desenho de transição; 3/ por fim, deixo algumas considerações reflexivas a fim de contribuir para outros questionamentos e o aprofundamento das epistemologias do cuidado ecofeminista. 


\section{Nanduty}

ISSN:2317-8590

\section{A PESSOA E O LUGAR - CONTEXTUALIZAÇÃO PRELIMINAR DA ANÁLISE}

Annalisa Bellu é italiana, filha de mãe inglesa e pai sardo. Nasceu no início da década de 70, do século XX, e viveu na Itália até 2002. É moradora de Campo Benfeito há, aproximadamente, 12 anos, mas vive em Portugal há 17. Anna foi morar em Lisboa logo após o nascimento de sua filha com o Tiago, Alice. Viveram, os dois mais a miúda, em Lisboa por dois anos e decidiram ir viver em Campo Benfeito, na busca de construírem outra forma e organização da vida para os três. Passados 17 anos já vividos em Portugal, hoje Anna e seu companheiro, Tiago, aumentaram o núcleo familiar. Anna e Tiago são mãe e pai de Alice, Matía e Marco.

[Campo Benfeito? Como vocês chegaram aqui?]

Começamos $^{5}$ a vir aqui porque o Tiago sempre passou férias com a avó. A mãe nasceu aqui. Vim cá em 2000, a primeira vez. Vim com o Tiago, mais outras italianas e uma brasileira. Conheci a terra, o Teatro, os Laguaiz...

Campo Benfeito é uma aldeia desenvolvida no seio da Serra do Montemuro, a cerca de 1050 metros de altitude, pertencente à freguesia de Gosende, concelho de Castro Daire, na região da Beira Alta, em Portugal. Está hoje constituída com a presença de 51 pessoas, moradoras permanentes na aldeia. Existe um pequeno fluxo no trânsito social com outras pessoas que vivem na cidade e, eventualmente, retornam à terra familiar para um par de dias. Nas férias de verão, em especial no mês de agosto, a aldeia aumenta. Parece mesmo ampliar seus verdes e rochosos espaços para acolher as famílias reunidas em suas casas, erigidas em histórias familiares diferenciadas. Há uma interação geracional viva nas férias de verão. Além de, nesse período há o Festival Altitudes, do Teatro do Montemuro ${ }^{6}$, o que faz a aldeia receber pessoas vindas de outras origens, não necessariamente com vínculo local familiar.

\footnotetext{
${ }^{5}$ Esclareço que a partir daqui a narrativa apresentada pela Anna é transcrita, sem qualquer modificação, em itálico para distinguir a sua fala da análise que, em seguida, desenvolvo.

${ }^{6}$ Para informações sobre o Teatro do Montemuro: https://teatromontemuro.com/
} 


\section{Nanduty}

ISSN:2317-8590

Sobre a geografia da aldeia Maria Olinda Santana narra que:

A zona serrana de Montemuro, geograficamente, próxima de Trás-os-Montes, ostenta uma semelhança climática, orográfica e, consequentemente, de formas de vida similares às das aldeias do Interior transmontano. [...] $\mathrm{O}$ clima e o relevo dum lugar alto situado na serra do Montemuro não são propícios a culturas nobres, tais como: o trigo, o vinho e as frutas. Ao invés, a criação de gado bovino, ovino e caprino, o fabrico de laticínios, a produção de lã foram atividades econômicas praticadas, desde tempos imemoriais. [...] A aldeia de Campo Benfeito geograficamente está localizada numa encosta, sendo atravessada pelo rio Balsemão. (2016: 33-34)

E ainda, afirma Santana (2016) que o abandono do pastoreio e o da agricultura, ocorridos ao durante o século XX na comunidade local, estão a acabar com os sistemas tradicionais da agricultura sustentada do Montemuro. (SANTANA, 2016: 66)

Contrariando as adversidades do clima e da geografia da região, como acima descrito, Anna e Tiago, desde caminhos individuais diferenciados, trilhados em países diferentes - Itália e Portugal -, mas com uma cultura biológica comum, (como me disse Anna), escolheram Campo Benfeito para viver e produzir na terra. Dito de outra maneira, após passarem alguns períodos entre Lisboa e a aldeia, Anna e Tiago decidiram construir e reinventar a vida comum familiar na aldeia, com o cultivo, produção e inovações para a cultura alimentar, respeitando o equilíbrio com o ambiente local.

Anna fez licenciatura em ciências florestais em Florença, Itália. No último ano dos estudos foi para Lisboa realizar um intercâmbio Erasmus ${ }^{7}$ e conheceu o Tiago que cursava arquitetura da paisagem na capital portuguesa. Entre Portugal e Itália, o namoro que, segundo ela, não foi um namoro assim muito standard, resultou na gravidez da primeira filha do casal e ela, Anna, decidiu mudar para Lisboa, junto do Tiago. Ambos já estavam graduados quando nasceu a menina. Ele trabalhava na época num escritório de paisagismo em Lisboa. Mas, como narrado

\footnotetext{
7 “O programa Erasmus, acrónimo do nome oficial em língua inglesa, European Region Action Scheme for the Mobility of University Students (Plano de Ação da Comunidade Europeia para a Mobilidade de Estudantes Universitários), é um plano de gestão de diversas administrações públicas, que apoia e facilita a mobilidade académica dos estudantes e professores universitários através do mundo inteiro." Fonte: https://pt.wikipedia.org/wiki/Programa_Erasmus
} 


\section{Nanduty}

ISSN:2317-8590

pela Anna: O Tiago na altura já tinha decidido fechar o trabalho e concorreu pra um doutoramento e ganhou. E decidi fazer o mesmo. Olha, tentei! Não ganhei logo, depois fiz recurso e lá consegui. E na altura que eu fiz já tava grávida do Matía. [...] Comecei a bolsa ele já tinha... nem um ano tinha. E o meu trabalho do doutoramento foi com veados e... foi no norte de Portugal. Por isso na altura, já começamos a vir pra cá mais vezes [Campo Benfeito]. Os miúdos estavam só no infantário, então podíamos tirá-los da escola mais tempo e começamos a vir cá mais vezes porque eu e o trabalho do Tiago - também era nessa área, ele estava a estudar a vegetação aqui da zona e do Vale do Paiva, da bacia do Paiva. E ali começamos a ponderar mudarmos pra cá. Na altura, como ainda viajávamos, começamos a fazer uma hortita no campo. A experiência.... enfim! Foi uma série de coisas. Decidimos que gostávamos o suficiente daqui para mudar. Toda gente ficou a pensar que estávamos malucos, 'o que que vão lá fazer? Aquilo é o fim do mundo!'

\section{ORIGEM, OS PRIMEIROS ENCONTROS COM A TERRA E AS EXPERIÊNCIAS DA ANNA ENGENDRADAS NO CUIDADO PELA E COM A VIDA}

É assim: eu nasci no norte de Itália, meu pai era das forças armadas, então tava destacado perto de Verona. Mas ele é da Sardenha. E sempre quis voltar pra terra dele. Quer dizer, pra

ilha dele. É uma coisa muito típica dos sardos: forte ligação com a terra. Então, ele foi pedindo transferência... Mas, entretanto, antes de ser transferido comprou um pedaço de terra, relativamente perto donde vivia a mãe e a irmã [...]. Assim: menos de 1 hectare, pr'aí 8000 ou $6000 m^{2}$, não sei ao certo. E tinha uma vinha, um pomar de pereiras, e mais nada! Comprou aquilo e começou a ir pra lá de vez em quando, quando tinha férias...

Quando comprou isso eu era pequena, não sei dizer ao certo..., se calhar tinha uns 5 ou 6 anos. E começou a tratar daquilo. E nós íamos sempre de férias para a Sardenha. E, enfim, aquilo foi crescendo e depois conseguiu a transferência, foi destacado lá pra Sardenha, e fomos pra lá todos. Por isso, digamos que a quinta, não era uma quinta, mas sempre fez parte. Mesmo que nós não vivêssemos lá ao pé, era pr'aí 20 minutos, meia hora de onde vivíamos. Era 


\section{Nanduty}

ISSN:2317-8590

temático todos os domingos íamos comer à casa da minha avó e íamos lá. Portanto isso sempre fez parte. Eu sempre gostei assim da terra.

Minha mãe é inglesa e gosta de jardim, então, ela sempre teve um cantinho com flores lá na quinta pra ela. E gosta. Assim, de trabalhar naquilo; trabalha bastante. Minha tia também..., todos.

Sempre ajudei, mais ou menos, né? De pequena não é que eu fizesse muita coisa, mas eu gostava. E minha avó também ensinava-me coisas, minha vó também gostava da quinta. [...] ela era de uma familia pobre, sempre trabalharam muito, não é? E ela sempre gostou também de plantar, de cultivar! E ensinava-me coisas. Era muito cuidadosa. Eu lembro-me de irmos lá na quinta e ela plantava os feijões e depois o regava com uma latinha, uma lata de feijão, ia buscar água e ia regar assim..., muito, muito cuidadosa. Mas pronto. Ela ia contando coisas e sempre fiquei aí fascinada com o mundo da agricultura.

As pedagogias de socialização primária significam parte dos conhecimentos que nos formam e que, ao longo da vida, transformamos, revisitamos e reinventamos em nossas estórias e experiências. A relação da Anna com a quinta da família, desde criança, guarda estreita ligação com os ensinamentos passados pela avó que, na sua memória, era uma pessoa muito cuidadosa no cultivo dos alimentos. O cuidado com a vida familiar, na sua estória, está atrelado ao cuidado com a terra e com os produtos/alimentos que essa fornece. Assim foi o início das percepções da Anna, menina, sobre a responsabilidade do cuidar daquilo que nos alimenta e da onde estamos produzindo nossas relações, sejam essas entre as pessoas humanas ou não. Nessa mesma direção de pensamento, Donna Haraway (2015) lembra que a história é realizada por espécies orgânicas e forças/personagens abióticos copartícipes da pulsão da vida, na mesma casa na qual todas/os nós habitamos, chamada Terra. Pois, a interdependência da vida vai além das relações sociais, políticas e econômicas reconhecidas nas estruturas do sistema capitalista e da racionalidade instrumental modernas. 


\section{Nanduty}

ISSN:2317-8590

Em linha com Amaia Pérez Orozco (2006), falar sobre a sustentabilidade da vida não significa dar uma nova definição fechada sobre economia, mas sim oferecer uma solução aberta que transcenda o par de opostos, antagônicos e hierarquizados, estabelecido nas estruturas do poder hegemônico que insiste em incutir no imaginário social o que é trabalho (se remunerado e gerador de bens à economia do mercado) e o que não é trabalho, por não estar diretamente empregado no ganho de capital financeiro, e que sim, guarda a idéia básica de cuidar da vida como objetivo central. A cultura imposta pelo sistema capitalista, sustentada pelo patriarcado, não só expulsou os trabalhos do cuidado, enquanto produção incessante da vida, da economia monetária, como também excluiu da ciência e dos cânones científicos todos os conhecimentos e competências criados, imaginados e transmitidos a partir das experiências de muitas mulheres do mundo. (CUNHA; VALLE \& VILLAR-TORIBIO, 2019)

Assim, em harmonia com Anna Bosch et al (2004) entendo que:

[...] trabajo en sentido amplio es una actividad que se desarrolla de manera continua y que forma parte de la naturaleza humana. De hecho, entendemos el trabajo como la práctica de creación y recreación de la vida y de las relaciones humanas. En la experiencia de las mujeres, trabajo y vida son la misma cosa. El trabajo nos permite crear las condiciones adecuadas para que se desarrolle la vida humana partiendo de las condiciones del medio natural. (2004: 9)

Ao recordar o tempo em que passava na quinta, com sua avó a lhe ensinar o cultivo, a ordem do plantio, a continuidade do tratamento cuidadoso diário com os alimentos que produzia, Anna - ao pé de um dos galinheiros e sem largar das mãos uma das bandejas de madeira que limpava - exclama:

\section{Xxxxxiiiiiii tá cheio de bicho!}

Tem uma praga que as galinhas ganham, por isso que eu trouxe lixívia, que não é nada bom, mas é melhor do que outros produtos. Quero ver se matamos. Porque são bichos, são ácaros, o que fazem é: chupam o sangue das galinhas. E elas não crescem, e se a infestação for muito grande podem até morrer, inclusive. Ficam anêmicas. É uma espécie de vampiros de galinhas, então vou ter que limpar toda essa coisa. Eu até limpei não tem muito tempo, mas 


\section{Nanduty}

ISSN:2317-8590

como são muitos... O ideal era - depende do número das galinhas que há-mas digamos assim, o ideal era, sei lá, uma vez por semana, de duas em duas semanas. E isso dá muito estrume, né? Agora, eu nem sempre faço isso.

[Fica duro, né?]

Pois fica. Porque eles dormem aqui e compartem isso..., mas pronto! Ai, ai, que bicho nojento! [os ácaros]E ele vai mesmo nas frinchas [...] É complicado rebelar a praga! Os bichinhos são minúsculos e enfiam-se, não é?, nessas frinchas e saem, principalmente, à noite. Os bichos são atacados, principalmente, à noite. E... bem! Agora, matei muitos. O que é..., daqui uma semana tenho que..., porque põem ovos, não é? Daqui a uma semana tenho que voltar a fazer isso até dar cabo deles.

[Tem período..., será? Por causa do calor.]

Sim, com o calor, sim aumentam! Uma coisa que funciona bem, que reduz bastante, é a cinza. Só que agora não tenho, já usei toda. Eu, normalmente, ponho muita cinza assim nas frinchas e eles num gostam de andar nas cinzas porque corta a cutícula e morrem mesmo.

[...] tem que ser mesmo o pozinho, mesmo cinza, ou então uma coisa que se usa, mas tem que se comprar, e não sei o quanto é sustentável, pra ser sincera, que chama terra de 'diatomea'. 'Diatomea' são microalgas, nem sei bem se são algas, por acaso [...]. São seres unicelulares, digamos, que tem uma casca de sílica, que corta. É como se fosse de verde pra cinza, uma farinha, mas corta um bocadinho. Até tem um tipo, ou uma dimensão que até se pode comer; há pessoas que usam mesmo como antiparasitário pro organismo humano, pros animais etc., na agricultura biológica porque tem essa coisa que corta as cutículas dos parasitas e os bichinhos acabam por morrer. Agora, isso não é fácil de encontrar, mas encontra-se na 'internet' - o que eu tenho alguma dúvida relativamente à sustentabilidade do produto porque é um produto que é minerado, basicamente. São algas que encontram-se em depósitos antigos... é uma exploração... não estudei bem a coisa... não tenho a certeza de que seja sustentável. Dizem 


\section{Nanduty}

ISSN:2317-8590

que funciona muito bem, mas... não é? A cinza é mais sustentável porque a gente faz fogueira e vem cinza. Pode não ser tão eficaz, mas funciona bastante bem. [...] Por isso que é tão importante pros animais fazer banho de pó. Porque libertam-se dos parasitas.

[A lixívia mata mesmo?]

Mata... não sei... claro que a lixívia não é bom produto, mas ela evapora, portanto, não fica. Vai evaporando e não é tão perigosa. Não é inócua, né? Mas é mesmo nas frinchas.... eu ponho e logo começam a sair [...]. Aqui já não tem muitos.

O cuidado por ela investido no tempo em que matava os vampiros de galinhas, a meu ver, implica a prática da ecologia dos saberes (SANTOS, 2014) que coloca em tensão dialógica a diversidade de conhecimentos do mundo e está atenta à importância, à validade e ao significado que cada um tem para a resolução dos problemas concretos enfrentados. Os ácaros morrem com a pulverização das cinzas. Anna, na prática continuada de criar galinhas, já experimentou, observou e constatou a eficácia sustentável e inofensiva para os animais quanto à utilização das cinzas e mesmo da lixívia. Ela reúne os conhecimentos científicos que acumulou na sua formação pessoal para escolher e trabalhar com os recursos disponíveis que melhor podem responder às suas necessidades, sem afetar, ou minimamente afetar, o bem estar dos seres ali envolvidos. Ela pondera o que usar, quando e em que circunstâncias. Mesmo atenta à mercantilização de produtos, supostamente, ecológicos, ela expõe a dúvida sobre a procedência e a forma de extração das microalgas (diatomea). Pois os limites do planeta não significam um problema alheio a sua vida, nem tampouco algo suplantado para um futuro incerto e não sabido, como afirma Amaia Pérez Orozco (2017):

[...] sino como un problema en el que ya estamos instaladxs. Esta producción en constante crecimiento requiere un nivel de consumo de recursos naturales y energía y conlleva, asimismo, un ritmo de emisión de residuos tal, que ya hace tiempo que hemos encontrado en una fase de translimitación: vivimos de los ahorros del planeta. Toda nueva producción implica la depredación de la riqueza natural. (OROZCO, 2017: 213) 


\section{Nanduty}

ISSN:2317-8590

Além do mais, essa depredação das riquezas naturais do planeta não é repartida de maneira equitativa por todas as comunidades humanas, pelo contrário. A superação dos limites dos recursos da Terra está inextricavelmente ligada ao crescimento da desigualdade global, uma vez que resulta insustentável os modos de produção e consumo implementados pelo modelo desenvolvimentista do capitalismo neoliberal do século XX (PÉREZ OROZCO, 2017; MIES, 2014 \& FEDERICI, 2014, 2018). Cabe aqui esclarecer que para pensarmos em sustentabilidade, sem cairmos na incompatibilidade do modelo do desenvolvimento econômico contemporâneo, implica a compreensão de que o ser humano necessita de um equilíbrio "consigo mesmo e com o planeta, mais ainda, com o universo. [...] refere-se ao próprio sentido do que somos, de onde viemos e para onde vamos, como seres do sentido e doadores de sentido a tudo o que nos cerca". (GADOTTI, 2005: 16)

Movida pelo trabalho junto com a terra, na aldeia que adotou para morar e construir uma vida junto com seu companheiro, a filha e os filhos, Anna narra que da hortita experimental iniciada pelo casal, hoje ela cuida de oito terrenos distribuídos na geografia de Campo Benfeito. E o percurso que ela assumiu, desde o começo, foi experimental.

\subsection{A DESCOBERTA DA PERMACULTURA E FACETAS DE UM DESENHO DE TRANSIÇÃO}

[...] continuamos a nossa hortita; mesmo enquanto eu fazia o doutoramento o que eu gostava mais era de trabalhar na horta. Acabei o doutoramento, mas percebi que não era... não era aquilo, não sei... não era aquilo! Já tinha perdido o entusiasmo. E tava sempre com mais entusiasmo na agricultura e... e entretanto, durante esses anos eu comecei a fazer pesquisas, assim por minha conta, e descobri a permacultura. Que por acaso, nunca fiz nenhum curso. Foi por acaso... não sei se já tinha contado isso, não me lembro... eu tava... acho que já te contei. Que eu tinha [...], lembrei-me de ter visto há uns anos antes um documentário relativamente a um senhor que vivia também nos Alpes, na Áustria, portanto zona de montanha, que conseguia cultivar imensas coisas. Enfim, consegui ... por ser um clima parecido porque aqui... o que limita aqui é o frio, o frio na primavera. Nem é tanto no inverno. Mas na primavera. As geadas até 


\section{Nanduty}

ISSN:2317-8590

muito tarde. Então... lá consegui encontrar o homem, foi muito difícil porque já lá não lembrava o nome dele, mas lá consegui e foi assim que descobri o que era permacultura.

Sobre a permacultura entendo significar uma variante conceitual inserida no arcabouço sistêmico da agroecologia. Além de o termo agroecologia remontar à década de 20, (século XX), e a permacultura ter sido a tradução utilizada para a expressão inglesa permanent agriculture, criada por Bill Mollison e David Holmgren, na década de 70 (século XX), Miguel Altieri (2010) lembra que durante séculos as agriculturas dos países periféricos (e também os semi-periféricos) foram construídas por meio dos recursos locais da terra, água e demais bens naturais, a partir dos conhecimentos de indígenas, camponesas/es, agricultoras/es locais que nutriram biológica e geneticamente toda a produção cultivada. E que este modelo microcósmico de agricultura tradicional proporciona formas de produção ecológica, biodiversa, local, sustentável e socialmente justa que formam a base da soberania alimentar (ALTIERI, 2010).

Como dito acima, o termo agroecologia data dos anos 1920, Luciana Jacob (2019) explica que surgiu a partir dos:

[...] primeiros diálogos entre a ecologia, a agronomia, a zoologia e a botânica e fisiologia de plantas. A epistemologia da agroecologia é composta, em sua gênese, pela ideia da aplicação de conhecimentos ecológicos na agricultura. A ampliação e expansão do conceito na segunda metade do século passado foram devidas, em grande parte, à introdução da ideia de agroecossistema por Eugene Odum na década de 1970 e pelo aumento das preocupações ecológicas e ambientais na década de 1980 . O conceito e sua epistemologia foram tomando, no decorrer do tempo, diferentes delineamentos de acordo com as especificidades dos contextos em que se desenvolveram. (JACOB, 2019)

Sobre a permacultura, Bill Mollison (1998), ao final de sua introdução, sintetiza assim:

A permacultura é um sistema pelo qual podemos existir no planeta Terra utilizando a energia que está naturalmente em fluxo e é relativamente inofensiva; e, da mesma forma, pelo uso de alimentação e de recursos naturais que sejam abundantes, sem destruirmos a vida na Terra. Todas as técnicas para a conservação e a restauração da Terra já são conhecidas; o que não é aparente é alguma nação ou um grupo grande de pessoas que esteja preparado para efetuar a mudança. No entanto, milhões de pessoas comuns estão começando a fazê-la sozinhas, se a ajuda das autoridades públicas. (MOLLISON, 1998: 13) 


\section{Nanduty}

ISSN:2317-8590

Fiz a pesquisa, punha lá no motor de pesquisa: agricultura, alto, cultivo na montanha, não sei quê... e lá encontrei um sítio de um americano que tinha os vídeos relativamente a esse homem. E que esse senhor americano tinha criado um fórum que para a permacultura. É um fórum de discussão. É um fórum enorme que tem pessoas de todo o mundo. Se calhar deve ser o maior, relativamente, a permacultura. Tem base nos Estados Unidos, mas tem em todo lado; tem gente aqui em Portugal que tá nesse fórum. Descobri um montão de coisas, fui lendo, sempre a descobrir mais coisas e achei! Pronto, achei logo que fazia sentido pra mim o que eles diziam da permacultura. Quer do ponto de vista prático, né? A permacultura, ao fim e ao cabo é uma maneira de ordenar, não é?, o espaço agrícola e de maneira funcional eficaz, não é? E tem uma data de coisas dentro disso, ou seja, tira partido da observação da natureza e tenta replicar o que funciona na natureza no mundo agrícola. E de maneira que seja útil para o homem e de maneira que seja sustentável para o ambiente, não é? Para que não estrague e que perpetue a fertilidade, a conservação da água..., tem tudo. É muito interessante desse ponto de vista. Depois tem uma vertente ética que também é interessante, quer o cuidado com o ambiente, quer com o cuidado com as pessoas, com a justiça, não é? A divisão da riqueza entre todos, entreajuda, tem umas coisas interessantes... Tem também coisas que às vezes... enfim, como tudo! Coisas que podem não fazer sentido. Às vezes encontra-se assim, pesquisando coisas de permacultura, encontram-se... parece uma coisa assim de 'frick', de gente... O Tiago diz sempre isso, ele não é muito fã disso. Mas também não é muito fã porque não conhece, tem um preconceito, acho eu. Mas às vezes encontram-se vídeos de encontros de permacultura onde são um bando de jovens... a dançar... enfim, parecem aqueles festivais alternativos. Mas isso é só uma faceta, não interessa. Não é isso que me interessa na permacultura. Portanto eu comecei a fazer pequenas experiências, tentar por em práticas algumas coisas que funcionam, outras coisas não...

[Essas terras que vocês adquiriram não tinham nada, tinham? Digo cultivadas.]

Essa cá embaixo, essa grande cá embaixo, era da tia Agustinha, (não sei se já conheceste uma tia do Tiago, uma irmã da vó do Tiago que vive aqui), que tava a cultivar. E depois nós já... 


\section{Nanduty}

ISSN:2317-8590

Aliás, na altura, antes de nós fazermos a partilha, ela deixou de cultivar, ou só cultivava um bocadinho e nós começamos a fazer o resto. Portanto, esse já tinha horta. Depois, no início, fizemos uma do outro lado do ribeiro que acho que essa não tinha nada na altura. Nós começamos uma coisa pequena depois fomos ampliando. Mas essa passou para um tio do Tiago, portanto já não é nossa. E fizemos várias. Essa, por exemplo, só ano passado que fizemos. Essa cá embaixo era uma mata, que já tava a imenso tempo, uns 30 anos. Era só silvas, uma data de árvores e não se conseguia entrar. Mas eu sempre gostei dela. Há anos que dizia eu quero comprar esta para a horta. Essa também era só silvas.

A galinha, por exemplo, é um animal muito utilizado na permacultura; é um animal extremamente útil para o agricultor. Porque é... assim..., é um animal que come tudo, não é esquisito. Come os restos de cozinha, de agricultura, e transforma em carne e ovos e ao mesmo tempo come as ervas, portanto pode limpar o terreno... até usam as galinhas numa coisa que chama o trator de galinha. Não sei se já ouviste falar. Trator de galinhas. Fazem assim, como se fossem pequenos galinheiros, com uma rede, assim como um túnel pequeno e depois colocam num bocado de terra que queres cultivar. Limpam aquilo tudo, estrumam e até arejam aquilo tudo... Porque as galinhas esgravatam a terra. Depois põe no outro lado e podes cultivar. Mexes assim só um bocadinho e nem precisas de trabalhar. Elas que fazem tudo.

Aqui por exemplo, no inverno passado, tínhamos um recinto e tavam aqui as galinhas, bem isso foi super simples de trabalhar. Mexemos um bocadinho a terra, estava estrumado, depois foi só plantar. E olha isso tudo que deu. E chove, né? Chove aqui, a água percorre e os nutrientes estão todos ali. Nunca tive 'courjettes' tão grandes. A galinha é um animal que não requer tratamentos especiais, tens que garantir segurança, não é? Para que não venha a raposa para os comer. Uma certa limpeza por causa dos ácaros. Mas não dá muito trabalho. Sei lá... as vacas, as ovelhas, tens que ir ao monte; requerem mais investimentos do tempo. A galinha é um animal mais fácil de se gerir. 


\section{Nanduty}

ISSN:2317-8590

[Aqui você tem só galinha? Não tem coelho...?]

Sim. Já falamos de pato e coisas assim, mas é... Mas não sei. É preciso... não sei. É porque eu gosto de criar condições boas pra elas, não é? Portanto, é preciso espaço, é preciso uma gestão do espaço que seja boa pra todos. Portanto, pra quem trabalha, pra mim, e para os animais; portanto, por enquanto, se calhar, não. Pensamos nos patos por causa daquele outro terreno. Que tem o laguinho, mas ali precisa fazer uma vedação... por causa dos javalis... Ali entram à vontade.

Durante muitos séculos foram seres-mulheres as responsáveis pela seleção, produção e conservação das sementes, do cultivo, da organização do plantio; utilizando os recursos disponíveis de maneira equilibrada com o meio comunitário - humano e não-humano (LEÓN, 2009; SHIVA, 2018 \& FEDERICI, 2018). Pela observação, o cuidado e o trabalho continuado elas engendram técnicas e conhecimentos geracionalmente transmitidos, e também na troca comunitária, que alimentam práticas ecofeministas do cuidado com a vida, por meio da produção com a terra, mesmo sem assim nomearem.

A prática do cuidar da vida apresentada na narrativa da Anna aponta, nessa análise inicial da investigação em construção e pelo convívio e no diálogo dos nossos conhecimentos - os da Anna e os meus - para um desenho de transição (DT) ontológico para a necessária transformação socioeconômica e política humana, como propõe Arturo Escobar (2017):

Los DT parten de la noción de que las crises ecológicas y sociales contemporáneas son inseparables del modelo de vida social que se ha vuelto dominante en los últimos siglos, categorizado como industrialismo, capitalismo, modernidad, (neo)liberalismo, antropocentrismo, racionalismo, patriarcado, secularización o, incluso, civilización judeo-cristiana. (ESCOBAR, 2017: 247)

Para pensar uma economia centrada na vida, para a comunidade humana e não-humana seguirem coparticipando do mesmo evento orgânico Terra, em linha com Escobar (2017), implica a re/constituição dos mundos relacionais, nos quais a economia é recolocada na sociedade e no meio vital onde cada indivíduo está. Esta interação da comunidade humana com a não-humana e 


\section{Nanduty}

ISSN:2317-8590

com os conhecimentos de proximidade do saber, ser e fazer o mundo onde estão em manifestação representa uma das fraturas existentes nas linhas abissais (SANTOS, 2014) contemporâneas, forjadas na compreensão ontológica de que somos simplemente, ni siquiera principalmente, observadores distanciados sino participantes y diseñadores que se articulan con el mundo al estar inmersos en él. (ESCOBAR, 2017: 278)

Anna, seu trabalho e, penso, sua própria existência está marcada pela relação e produção com a terra e com toda manifestação viva do/no local onde decidiu viver com sua família, mesmo sem o dizer. Toda narrativa aqui trazida mostra essa percepção de que a vida está em tudo e em todos os seres. Contrária à lógica do racionalismo instrumentalizado pelo sistema do capitalismo-patriarcal e colonial moderno, no qual foi criada e formada, ela investe na ação e sentimento com a terra o cuidado para o bem estar de toda vida que a cerca e que com ela interage nas práticas cotidianas.

\section{REFLEXÕES FINAIS}

Rememoro que o presente trabalho apresenta uma análise preliminar de fragmentos de um diálogo de natureza biográfica com Annalisa Bellu, na aldeia de Campo Benfeito, Serra do Montemuro, região da Beira Alta, em Portugal. O objetivo foi identificar nas estratégias e práticas do cuidado com a vida, por ela imaginados, construídos e realizados, algumas das fraturas existentes nas linhas abissais contemporâneas que, insistem em impor uma hegemonia de poder fundamentada no sistema capitalista neoliberal que, por sua vez, é sustentado nas práticas coloniais de dominação e legitimado pela heteronormatividade que mantém a tensão - acelerada em destruições incontornáveis - da guerra contra a vida.

Estas práticas e maneiras de organizar, gerir, produzir e manter a vida que partem da compreensão da ecodependência dos seres vivos, manifestados na multifacetada forma que se apresenta, e que põem a centralidade da vida na construção relacional - humana e não-humana -,

socioeconômica e política comunitária, significam práticas ecofeministas, mesmo sem expressá-lo, diretamente. Além de que o protagonismo das mulheres no trabalho com a terra para 


\section{Nanduty}

ISSN:2317-8590

a produção alimentar familiar e comunitária em harmonia, equilíbrio e cooperação com o meio vital no qual vivem, expande-se em evidência nos diferentes espaços do mundo.

Reconheço que essas práticas ecofeministas do cuidado corporificam o novo ethos pró-comunal necessário às transformações relacionais e organizacionais da vida humana no e com o planeta, em espaços distintos, respeitados as necessidades e contextos existentes.

Annalisa Bellu guarda da relação com a avó o conhecimento do corazonar para produzir. Dos fragmentos da narrativa biográfica da Anna aqui trazidos identifico, a um só tempo, possibilidades abertas e em reconstrução para a expansão de desenhos de transição ontológica para a realização de outro ethos planetário; além de que, compreendo que as suas práticas cotidianas fortalecem as fraturas existentes nas linhas abissais divisoras da realidade do mundo e consubstanciam a conformação de uma teoria ecofeminista contextualizada na prática do cuidado com a vida.

\section{REFERÊNCIAS BIBLIOGRÁFICAS}

ALTIERI, Miguel A. 2010. Agroecologia, agricultura camponesa e soberania alimentar. Tradução de Bruno L. Aretio-Aurtena e Sofia Lizarralde Oliver. Revista NERA, Presidente Prudente, 13(16):22-32.

BOFF, Leonardo. 1999. Saber cuidar. Ética do mundo. Compaixão pela terra. Petrópolis, Vozes. . 2000. Ethos mundial: um consenso mínimo entre os humanos. Brasília, Letraviva.

BOSCH, Anna; CARRASCO, Cristina; GRAU, Elena. 2004. "Verde que te quiero violeta. Encuentros y desencuentros entre feminismo y ecologismo". Ponencia presentada en IX Jornadas de Economía Crítica, Universidad Complutense de Madrid. In: https://www.fuhem.es/media/cdv/file/biblioteca/Boletin_ECOS/10/verde que te quiero violeta. pdf (acessado em 05 de dezembro de 2019).

CUNHA, Teresa. 2015. Women InPower Women. Outras economias criadas e lideradas por mulheres no Sul não-imperial. Buenos Aires, CLACSO.

. 2017. Todo o trabalho é produtivo: economias de abundância e da sobriedade. In: Xoán Hermida González (coord.). [Re]Pensar a democracia. Compostela, Obencomún, pp. 101-134.

; VALLE, Luísa de Pinho. 2019. O respeito à economia da vida e as pedagogias ecofeministas. Reflexões sobre a prática da agroecologia e do hamutuk. Otra Economía, Buenos Aires, 12(22):238-252.

; _ _ VILlaR-TORIBIO, Cristina del. 2019. Cuidado. Dicionário Alice. In: http://alice.ces.uc.pt/dictionary/?id=23838\&pag=23918\&id lingua=1\&entry $=25288$ (acessado em 09 de dezembro de 2019) 


\section{Nanduty}

ISSN:2317-8590

DUSSEL, Enrique. 1993. 1492: O encobrimento do outro: a origem do mito da modernidade: Conferências de Frankfurt. Tradução de Jaime A. Classen. Petrópolis, Vozes.

ESCOBAR, Arturo. 2017. Autonomía y diseño: la realización de lo comunal. Buenos Aires, Tinta Limón.

FALS BORDA, Orlando. 2009. Una sociología sentipensante para América Latina. Buenos Aires, CLACSO.

FEDERICI, Silvia. 2018. Revolución en punto cero. Trabajo doméstico, reproducción y luchas feministas. Tradução de Carlos Fernández Guervós y Paula Martín Ponz. Madrid, Traficantes de Sueños.

. 2014. Calibán y La bruja. Mujeres, cuerpo y acumulación originaria. Tradução de Verónica Hendel y Leopoldo Sebastián Touza. Madrid, Traficantes de Sueños.

GADOTTI, Moacir (2005), Pedagogia da Terra e cultura da sustentabilidade. Revista Lusófona de Educação, Campo Grande, 6(6):15-29.

GUERRERO, Patricio. 2010. Corazonar: una antropología comprometida con la vida. Miradas otras desde Abya-Yala para la decolonización del poder, del saber y del ser. Quito, Ediciones Abya-Yala.

HARAWAY, Donna. 1988. Situated knowledges: The science question in feminism and the privilege of partial perspective. Feminist studies, Maryland, 14(3):575-599.

. 2015. Anthropocene, Capitalocene, Plantationocene, Chthulucene: Making Kin. Environmental Humanities, Durham, 6(1):159-165.

JACOB, $\quad 2019 . \quad$ Luciana. $\quad$ Agroecologia". Dicionário Alice. In: http://alice.ces.uc.pt/dictionary/?id=23838\&pag=23918\&id_lingua=1\&entry $=24435 \quad$ (acessado em 06 de dezembro de 2019).

LEÓN, Irene. 2009. Las mujeres gestoras de la Soberanía Alimentaria. In: HERRERO, Amaranta; VILELLA, Mariel (orgs). Las Mujeres Alimentan al Mundo. Soberanía Alimentaria en defensa de la vida y el planeta. Barcelona, Entrepueblos-Entrepobles-Entrepobos-Herriarte: 16-39.

MIES, Maria. 2014. Patriarchy and Accumulation on a World Scale: Women in the International Division of Labour. Londres, Zed Books.

; SHIVA, Vandana. 2014. Ecofeminismo: teoría, crítica y perspectivas. Tradução de Mireia Bofill, Daniel Aguilar, Eduardo Iriarte y Maria Pérez Sánchez, y Joan Soler. Barcelona, Icaria-Antrazyt.

MOLLISON, Bill; SLAY, Reny Mia. 1998. Introdução à permacultura. Tradução de André Luis Jaeger Soares. Brasília, MA/SDR/PNFC.

MURARO, Rose Marie; BOFF, Leonardo. 2002. Ponto de mutação. In: Feminino e masculino: uma nova consciência para o encontro das diferenças. Rio de Janeiro, Sextante.

PINTO, Maria Jesús I. 2009. Mujeres campesinas e indígenas, mujeres abriendo caminos en defensa de la vida, de las personas y del planeta. In: HERRERO, Amaranta; VILELLA, Mariel (edit.). Las mujeres alimentan al mundo. Soberanía Alimentaria en defensa de la vida y el planeta. Barcelona: Entrepueblos-Entrepobles-Entrepobos-Herriarte: 170-183.

PÉREZ OROZCO, Amaia. 2006. Perspectivas feministas en torno a la economía: el caso de los cuidados. Madrid, Consejo Económico y Social. 


\section{Nanduty}

ISSN:2317-8590

. 2017. Subversión feminista de la economía. Aportes para un debate sobre el conflicto capital-vida. $3^{\mathrm{a}}$ ed. Madrid, Traficantes de Sueños.

QUIJANO, Aníbal. 2000. Colonialidad del Poder, Eurocentrismo y América Latina. In: LANDER, Edgardo (org.). Colonialidad del Saber, Eurocentrismo y Ciencias Sociales. Buenos Aires, CLACSO-UNESCO: 201-246.

. 2009. "Colonialidad del poder y descolonialidad del poder". In: Conferencia en el marco del XXVII Congreso de la Asociación Latinoamericana de Sociología, Buenos Aires. In: http://www.ceapedi.com.ar/imagenes/biblioteca/libreria/51.pdf (acessado em 19 de dezembro de 2019).

SANTANA, Maria Olinda R. 2016. Campo Benfeito: uma aldeia de Montemuro. Enquadramento geográfico e percurso histórico. Porto-Portugal, UTAD, CETRAD.

SANTOS, Boaventura de Sousa. 2009. Para além do pensamento abissal: das linhas globais a uma ecologia de saberes. In: SANTOS, Boaventura de Sousa; MENESES, Maria Paula (orgs.). Epistemologias do Sul. Coimbra, Almedina: 23-71.

. 2014. Epistemologies of the South. Justice against Epistemicide. Boulder/Londres, Paradigm Publishers.

SHIVA, Vandana. 2013. Making Peace with the Earth. Londres, Pluto Press.

. 2018. ¿Quién alimenta realmente el mundo? El fracaso de la agricultura industrial y la promesa de la agroecología. Tradução de Amelia Pérez de Villar. Madrid, Capitán Swing.

SVAMPA, Maristella. 2013. Resource Extractivism and Alternatives: Latin American Perspectives on Development. In: Permanent Working Group on Alternatives to Development (org.). Beyond Development Alternative Visions from Latin America. Transnational Institute Rosa Luxemburg Foundation: 117-143.

. 2015. Feminismos del Sur y ecofeminismo. Nueva Sociedad, Buenos Aires, 256:127-131.

VALLE, Luísa de Pinho. 2017. El ecofeminismo como propulsor de la expansión de la racionalidad ambiental. Tradução de Claudia Jana Sinibaldi Bento. Ecología Política, Barcelona, 54, pp. 28-36.

. 2019a. "Ecofeminismo". Dicionário Alice. Coimbra, Centro de Estudos Sociais - CES.

In: $\quad$ http://alice.ces.uc.pt/dictionary/ $\mathrm{id}=23838 \& \mathrm{pag}=23918 \& \mathrm{id}$ lingua $=1 \&$ entry $=24270$

(acessado em 30 de abril de 2019).

. 2019b. Reflexões sobre práticas de artesania ecofeminista e pedagogia ambiental. Por uma política da natureza humana e não-humana. Saberes y prácticas. Revista de Filosofía y Educación, Mendoza, 4:1-19. 